\title{
Visualidades femininas: mostras de mulheres artistas no Brasil e em Portugal
}

\author{
REBECCA CORRÊA E SILVA
}

\section{Resumo}

O artigo apresenta uma das formas mais reconhecidamente geradoras, ressignificadoras e difusoras de visualidades: as exposições museológicas. Pretendemos demonstrar a relevância deste tipo de evento no contexto museal e para a sociedade, partindo de uma perspectiva interdisciplinar que relaciona a Sociomuseologia e o gênero. Tais conceitos foram aplicados à análise comparativa de duas recentes exposições dedicadas às mulheres artistas, vistos nos casos de Brasil e Portugal.

Palavras-chave:

Sociomuseologia, gênero, mulheres artistas 


\section{Female visualities: exhibitions of womens artists in Brazil and Portugal}

\section{REBECCA CORRÊA E SILVA}
Abstract
This article presents one of the most known regenerating means, re-signifying and diffuser of visualities: the museum's exhibitions. We intend to demonstrate the importance of this type of event in the museum's context and for the society, from a perspective that integrates sociomuseology and gender. These concepts were applied to a comparative analysis of two new recents exhibitions dedicated to the artist women, seen in cases of Brazil and Portugal. 
0 tema do presente artigo tem origem na pesquisa realizada para a elaboração da dissertação de mestrado em Gestão Cultural, na qual foi abordado o lugar das mulheres artistas - brasileiras e portuguesas - no cenário museológico atual do Brasil e de Portugal. Para compreender se havia de fato uma valorização das mulheres artistas por meio da visibilidade e do reconhecimento institucional dos museus daqueles países, foram analisados os casos de duas exposições temporárias: $\mathrm{O}$ Museu Sensível - uma visão da produção de artistas mulheres na coleção do MARGS, que teve lugar no MARGS - Museu de Arte do Rio Grande do Sul, em Porto Alegre, capital do estado do Rio Grande do Sul - Brasil; e a mostra Museu no Feminino - mulheres artistas na coleção do MFTPJ, apresentada pelo MFTPJ - Museu Francisco Tavares Proença Júnior, na região da Beira Interior e na cidade de Castelo Branco - Portugal.

O embasamento teórico sobre gênero, e sobre a mulher artista na história e nos museus, se deu principalmente através de Michelle Perrot (2007), Luciana Loponte (2005), Ana Paula Cavalcanti Simioni (2011), Filipa Vicente (2005) e Ana Mae Barbosa $(2003,2008)$. Na relação conceitual entre sociomuseologia e gênero, tivemos como principal contribuição e fonte de autores a tese de doutorado da investigadora portuguesa Aida Rechena (2011), pioneira nesta abordagem. O conceito de Sociomuseologia foi visto em Mário Moutinho $(1989,2007)$ e Mário Chagas (2007, 2009, 2010, 2012). As questões sobre expografia e comunicação museológica foram vistas principalmente a partir da museóloga Marília Xavier Cury (2009, 2010).

A metodologia de investigação recebeu uma abordagem de caráter analítico e comparativo, através da análise empírica das exposições realizadas no Brasil e em Portugal, baseado nos dados fornecidos pelo diretor(a) e curador(a) de cada mostra, aliado aos materiais de texto, vídeo e imagem 
obtidos via internet e pela visita à exposição O Museu Sensível. Paralelamente realizaram-se entrevistas com questões semi-estruturadas, utilizando o método de análise do tipo interpretativo, proposto por Severino (2002). Uma parte da entrevista foi aplicada a Gaudêncio Fidelis (MARGS) e a Aida Rechena (MFTPJ); outro conjunto de questões - sob o tema da Sociomuseologia e gênero, foi desenvolvido para o parecer do museólogo e Mário Chagas.

\section{Sociomuseologia e gênero - o papel social dos museus}

O processo de conscientização dos rumos da sociedade pósmoderna apresenta seus primeiros impactos a partir dos estudos culturais dos anos sessenta e setenta do século passado, que traziam na nova história e nas ideias precursoras da nova museologia uma visão aberta e em favor dos direitos dos historicamente marginalizados, configurada também na forma dos discursos feministas. As mulheres artistas, esquecidas pela historiografia oficial, também passaram a reivindicar sua representação naqueles espaços, que em grande parte, seguem os paradigmas tradicionais e obsoletos de instituições vernaculares, como é o caso dos museus. O Museu - enquanto entidade viva e em vias de se construir e reconstruir permanentemente - tem o dever de preservar e difundir a memória das artistas. É neste sentido que a Sociomuseologia demonstra ser a via mais adequada para a adoção de uma perspectiva de gênero, possibilitando aos museus um olhar crítico face à diversidade de atores sociais excluídos ou mal representados em suas coleções. Sobre a relevância da integração de uma postura social pela museologia, Chagas $(2012)^{2}$ indica que:

"A sociomuseologia ou museologia social tem um grande diferencial em relação à museologia clássica, na qual seja: a sua perspectiva crítica, dialógica, participativa, democrática. Nesse sentido, o que me parece relevante é, por intermédio de uma perspectiva crítica, a adoção de uma postura não-autoritária, anti-machista, antifascista e de valorização de uma nova representação da mulher."

Desde os movimentos feministas e suas consequências para os estudos sobre as mulheres, o gênero como categoria analítica foi assumido por diferentes áreas do pensamento e cada 
vez tende a ganhar espaço também na área da museologia e dos museus. Rechena (2011a, p.159), revela que apesar da irrevogável atenção que a Sociomuseologia tem com o social - que parte de uma abordagem no ser humano e na constituição do sujeito "não tem prestado muita atenção à questão da igualdade de gênero, nem refletido de forma aprofundada sobre a apropriação do conceito analítico gênero". De acordo com a autora, a Museologia ao incorporar a categoria analítica gênero, poderia contribuir para o resgate da memória e dos patrimônios femininos, construindo a igualdade de gênero tão almejada pela sociedade contemporânea. Em sua recente tese de doutorado, Rechena (2011a, p.35), coloca que a questão do gênero em Sociomuseologia pode ser abordada por dois diferentes vieses. O primeiro seria o da igualdade de gênero, que incide sobre a esfera da política e da gestão, o que muitas vezes leva a uma abordagem quantitativa do papel das mulheres na Museologia e nos museus, conduzindo à crescente feminização destas áreas. Já o segundo, como categoria analítica, estaria ligado à teorização das relações de gênero visto transversalmente pelas Ciências Sociais.

Podemos dizer que o Museu estaria cumprindo seu papel no processo democrático ao promover a igualdade entre os gêneros em todas as áreas de ação que ele atua na sociedade. Rechena (2011a, p.35) entende que a Museologia e a Sociomuseologia, ao integrarem uma perspectiva de gênero, passam a assumir a igualdade de gênero com estratégia de gestão, vista desde a organização, planejamento e execução até a avaliação das instituições e das ações museológicas. Com o foco no museu a serviço da sociedade e comprometido com a formação do ser humano, a Sociomuseologia poderia ser um caminho adequado para explorar as questões de gênero no museu. Isto conduziria a adoção de novas práticas em todos os setores daquela instituição, que sintetizaremos aqui em quatro: 1) na revisão de suas coleções e projetos curatoriais de modo a valorar as obras produzidas por artistas do sexo feminino; 2) na desnaturalização do olhar, promovendo uma visão crítica acerca da representação da mulher nestes espaços; 3) no repensar dos estudos de público, levando em conta a parcela feminina de visitantes; 4) na readaptação da mediação e materiais didáticos do museu em favor de uma discussão sobre gênero.

Neste estudo, priorizaremos o primeiro item: o lugar da mulher artista nos museus, da escuridão (o acervo) à luz(a exposição), enfim do esquecimento à memória, vistos nos casos de Brasil (MARGS) e Portugal (MFTPJ). 


\section{Museu Sensível e Museu no Feminino - a mulher artista nas exposições}

Como visto, este estudo priorizou o trabalho de análise das exposições, em detrimento à análise da coleção dos museus, valendo-se da ideia de que a exposição é o evento que possibilita uma maior aproximação entre o museu e o público, tornando-se um meio e um canal de diálogo. Como instituição a serviço da sociedade e do seu desenvolvimento, o Museu teria de prestar mais atenção a este momento, tendo em vista que as exposições que realiza são a expressão mais significativa do trabalho museal. Marília Xavier Cury (2009)³, museóloga de reconhecida autoridade no assunto, entende a exposição como exercício da linguagem própria dos museus e da forma de articulação dos objetos com signos em um discurso para o público, compreendendo a exposição como texto. Mais do que expor objetos, a exposição museológica exerce poder sobre a memória, desde seus critérios de seleção até a expografia e programas educativos, utilizando-se primordialmente de visualidades, com a finalidade primeira de comunicar.

De acordo com Michel Thévoz (1984), citado por Rechena (2011a, p.126), uma exposição marcante é uma transgressão conseguida, é a dissolução de um preconceito ou de uma contradição. E neste caso, a dissolução do preconceito contra as mulheres artistas encontra-se já na escolha curatorial em apresentar unicamente a obra de artistas mulheres.

As exposições selecionadas para compor o estudo apresentaram ao longo de três meses de duração como principal tema em comum as obras de mulheres artistas integrantes da coleção dos seus museus.

No Brasil, a exposição O Museu Sensível - uma visão da produção de artistas mulheres na coleção do MARGS ocorreu de 19 de dezembro de 2011 a 18 de março de 2012, tendo lugar no primeiro pavimento do Museu de Arte do Rio Grande do Sul Ado Malagoli - MARGS. Trata-se do principal museu de arte do Rio Grande do Sul, criado em 1954, pelo artista paulista e professor Ado Malagoli (1906 - 1994), localizado desde 1978 na Praça da Alfândega, zona central da cidade de Porto Alegre. Seu acervo abriga mais de 2.800 obras ${ }^{4}$ de artistas regionais (em sua maioria), nacionais e internacionais apresentados sob a forma de gravura, pintura, escultura e instalações contemporâneas, produzidas desde século XIX até a atualidade. Em sua atual gestão (2010 - 2014), o Museu possui como 
diretor o historiador da arte e curador Gaudêncio Fidelis, também responsável pela curadoria da mostra $O$ Museu Sensível. A exposição apresentou 250 obras de 131 artistas mulheres da coleção do $\mathrm{Museu}^{5}$, produzidas entre meados do século XIX até os dias de hoje. Exibindo obras de temáticas diversas, em técnicas variadas, sobre os mais diferentes meios, desde pinturas, esculturas e gravuras, passando por tapeçarias, cerâmicas e outros objetos artísticos. Convém acrescentar que o MARGS inaugurou em maio de 2014 outra exposição exclusivamente com obras de mulheres artistas, intitulada: "Útero, Museu e Domesticidade: gerações do feminino na arte”, desta vez sobre a curadoria de Ana Zavadil e com peças que até então não fazem parte do acervo do museu.

Em Portugal, a mostra Museu no Feminino - mulheres artistas na coleção do MFTPJ, aconteceu entre os dias 18 de junho e 25 de setembro de 2011, tendo lugar no Museu Francisco Tavares Proença Júnior - MFTPJ. O museu encontra-se instalado no Largo Dr. José Lopes Dias, atrás dos Jardins do Paço, na região da Beira Interior, cidade de Castelo Branco. Foi fundado pelo arqueólogo Francisco Tavares Proença Júnior (1883-1916) no ano de 1910, poucos meses antes da implantação da República. Seu acervo, conforme Rechena (2011a, p.294) divide-se em três coleções principais: arqueologia (provenientes da coleção de seu fundador), têxteis, e o Núcleo de Pintura Portuguesa Contemporânea. Destacam-se ainda exemplares da arte primitiva portuguesa, tapeçarias do século XVI e as suas famosas colchas de seda bordadas. A partir dos anos de 1980, passou também a incorporar obras de arte contemporânea e em 2010 adquiriu peças de etnografia, numismática e fotografia. O MFTPJ tem um acervo total com mais de 10.400 peças, sendo a maior parte composta por arqueologia. A supercategoria Artes possui 2.661 peças, contando com $35^{8}$ pinturas e 33 esculturas. Da coleção de pinturas, 6o são de mulheres artistas; e da coleção de esculturas, apenas uma pertence à uma mulher artista. As mulheres artistas são 18 representadas na coleção do MFTPJ, sendo uma delas espanhola. Na direção do MFTPJ desde abril de 2005, Aida Rechena, mestre e doutora em Sociomuseologia pela Universidade Lusófona, na altura ainda era chefe de Divisão da Cultura e Patrimônio Cultural da Câmara Municipal de Odivelas. À frente do projeto Museu no Feminino, que resultaria em duas exposições, Museu no Feminino: mulheres artistas na coleção do Museu Francisco Tavares Proença Júnior e Museu no Feminino 2 - as mulheres no olhar dos homens. Na ocasião da 
inauguração da primeira exposição, foi apresentada uma mesa-redonda com algumas das artistas que compunham a mostra, tratando do tema "Ser mulher artista plástica em Portugal". A exposição apresentou 27 obras das 18 artistas mulheres da coleção do Museu, produzidas em diferentes períodos. Exibindo obras com temáticas diversas em técnicas variadas, como pintura, fotografia, bordado e algumas esculturas.

Ambas as mostras buscaram desfazer o cânone da história da arte oficial que privilegia a produção dos homens. No texto do folheto da mostra, Gaudêncio Fidelis, curador de $\mathrm{O} M u s e u$ Sensível, afirma que a tradição clássica defendia uma "suposta genialidade masculina", e da mesma opinião compartilha Aida Rechena, curadora de Museu no Feminino, em seus comentários vistos no vídeo ${ }^{6}$ sobre a mostra onde destaca que a "história da arte e os grandes nomes muitas vezes são homens que surgem como os grandes gênios da arte". A curadora ressalta que a exposição buscou "mostrar a mulher que existe por trás da obra, e que também é um ser ativo e participante".

Conforme a entrevista com Fidelis ${ }^{7}$, no âmbito da história da arte, a fundamentação teórica da exposição $\mathrm{O} M u s e u$ Sensível "partiu de uma abordagem feminista das coleções baseado no texto de Linda Nochlin sobre a ausência da mulher artista da história e dos espaços museais". Enquanto Rechena, curadora de Museu no Feminino, revelou em sua entrevista ${ }^{8}$ que utilizou a proposta de Griselda Pollock, que, através do Museu Virtual Feminista (2007), traça complexas relações entre modernidade, feminilidade e representação. A qualidade de virtual não é dada no sentido de um cyber-museu, acessado através da internet, mas no sentido filosófico, que entende o virtual enquanto abstração e imaginação. As duas teóricas tratavam sobre a condição das mulheres artistas e reivindicavam uma mudança de paradigma. Nochlin questionava as razões da exclusão das artistas e propunha uma reformulação da história da arte, enquanto que Pollock compreendendo que uma outra história não era o bastante, defendia uma perspectiva não sexista e um olhar feminista das produções artísticas. Podemos sintetizar a contribuição destas teóricas concordando com Loponte (2005, p.248), para quem a diferença entre Nochlin e Pollock se caracteriza por "de um olhar mais formalista para um olhar mais político em relação à arte". Visto assim, podemos transferir esses olhares diversos sobre arte para as exposição museológicas: O Museu Sensível, identificado com o aspecto formalista e 
estético de apresentação das obras no espaço; e o Museu no Feminino, vinculado ao aspecto político, da própria condição social das artistas.

Já a partir dos próprios títulos conferidos às exposições $O$ Museu Sensível - uma visão da $<<$ produção $>>$ de artistas mulheres na coleção do MARGS, e Museu no Feminino - <<mulheres artistas $>>$ na coleção do MFTPJ, podemos ver os diferentes enfoques que cada curadoria proporcionou. E se observarmos bem, mesmo na grafia de artistas mulheres (MARGS) e mulheres artistas (MFTPJ) percebemos o que cada museu quis destacar de sua coleção. O MARGS demonstrou estar mais voltado para a obra produzida pelas artistas, enquanto que o MFTPJ preza as artistas produtoras das obras. Essa diferença de enfoque pode ser vista nos textos de divulgação das exposições, que destacam o objetivo principal de cada uma das mostras, no caso brasileiro "ser uma exposição acerca do lugar ocupado pela produção artística realizada por mulheres artistas na coleção do MARGS", e no caso português "tornar visíveis as mulheres por detrás das obras".

A segunda parte de cada um dos títulos também remete ao enfoque dado às obras em relação à coleção dos museus. No caso brasileiro apresenta-se como uma visão da produção das artistas da coleção, entendida como uma espécie de recorte, tendo em conta a existência de critérios de seleção mais definidos, pautados pelo que Fidelis chama na entrevista de "densidade artística”. Diferentemente da exposição portuguesa, que traz no título apenas a especificação de que a mostra trata das obras presentes na coleção, seguindo assim um critério mais livre de escolha, revelado por Rechena na entrevista, onde diz que "a escolha baseou-se única e exclusivamente no fato de serem mulheres e as suas obras pertencerem à coleção do Museu."

Por outro lado, existem aproximações entre as duas curadorias na maneira de pensar um museu que seja sensível e feminino, partindo de uma perspectiva feminista. Quando trata deste tema na entrevista, Fidelis destaca que "a palavra sensível refere-se ao próprio museu e a fragilidade e deficiência pela própria presença de suas lacunas no acervo". E salienta que Museu Sensível confere a qualidade de sensível ao Museu em si, não fazendo referência à obra das artistas na exposição. Enquanto Rechena, quando aborda a escolha do título na entrevista, explica que pretendeu "jogar com o fato de a palavra museu ser masculina na língua portuguesa. Ao introduzirmos a perspectiva de gênero passamos a ter um museu no feminino." 
O MARGS mostra-se sensível na valorização e reconhecimento da obra das artistas, quando apresenta uma posição autocrítica com relação à produção destas dentro de sua coleção e no contexto brasileiro. De acordo com Fidelis (in Bulhões, 2011), a mostra está "centrada em obras e não em individualidades". Ao contrário, o MFTPJ se interessa de forma mais intensa pela dimensão humana e busca compreender como se apresenta o lado feminino desse Museu, com relação aos anseios e expectativas das artistas inseridas em sua coleção, enquanto produtoras de arte. Para saber mais sobre as mulheres artistas de sua coleção, a curadora realizou entrevistas, colocou as legendas das obras com as palavras das próprias artistas e apresentou uma discussão com algumas das artistas na mesa redonda da inauguração da mostra.

Podemos dizer que o MARGS revela uma preocupação em apresentar a produção das artistas; e que de sua parte, o MFTPJ denota uma preocupação com as próprias artistas. Tanto o é que as perguntas enviadas às artistas tiveram um tom extremamente pessoal e buscavam responder como as artistas se sentiam em relação a sua classe, ao seu país, e ao espaço que o museu reserva para elas. O segundo caso parece-nos ser mais condizente com o pensamento da Sociomuseologia, que desloca a ênfase dos objetos/coleção para o ser humano, seja ele o produtor ou o consumidor.

Percebemos ainda que a curadoria de o Museu no Feminino foi mais influenciada pelos princípios da Sociomuseologia, que para Rechena (2011a, p.124) "surge como a vertente da Museologia que trabalha preferencialmente com as pessoas e com as ideias." Outro elemento que nos leva a essa conclusão, surge explicitamente nas entrevistas, onde Fidelis diz que de escolha das obras foi guiada pela qualidade artística, ao passo que Rechena revela que decidiu apresentar todas as obras das mulheres artistas da coleção, independentemente de serem obras conhecidas ou não.

As mostras prezaram o dever social dos museus, na medida em que tiveram como objetivo maior promover a visibilidade da obra de mulheres artistas através das exposições museológicas. Refletindo essa perspectiva na expografia da mostra, Fidelis (2011)9 revela: "Metaforicamente falando, saídas da escuridão da reserva técnica do museu, estas obras são trazidas à luz para o espaço da exposição". Com um pensamento semelhante, Rechena (2011b) escreve da seguinte maneira sobre essa iluminação conferida às artistas: "Iremos antes avaliar a 
possibilidade de desenvolver uma metodologia que utilize um olhar feminino sobre o trabalho museológico para resgatar das sombras esse universo apagado ou esquecido".

No caso brasileiro, a visibilidade das artistas promovida pela exposição faz relação com a visibilidade dada num sentido mais amplo, a do espaço público e das políticas culturais. De acordo com Fidelis $(2011)^{10}$, o desenho expositivo de disposição das obras foi pensado dentro de uma concepção do museu como um sistema reprodutivo feminino, "onde o foco será o renascimento da criatividade para a visibilidade pública, do conhecimento e da visualidade como potencial comunicativo".

O enfoque temático das duas curadorias, uma centrada nas obras e a outra nas criadoras, também se estende visualmente até a expografia.

A maior semelhança entre as duas expografias foi a exibição dos nomes das artistas dispostos em conjunto, apresentada tanto nos folhetos como no painel da entrada das mostras. No caso do MARGS, os nomes foram dispostos em forma de lista em duas colunas laterais; e no caso do MFTPJ, surgiam desencontrados espalhados por toda uma parede. Esse destaque aos nomes das artistas comprova a importância conferida ao reconhecimento e valorização destas por parte do público, prerrogativa que as duas exposições compartilhavam.
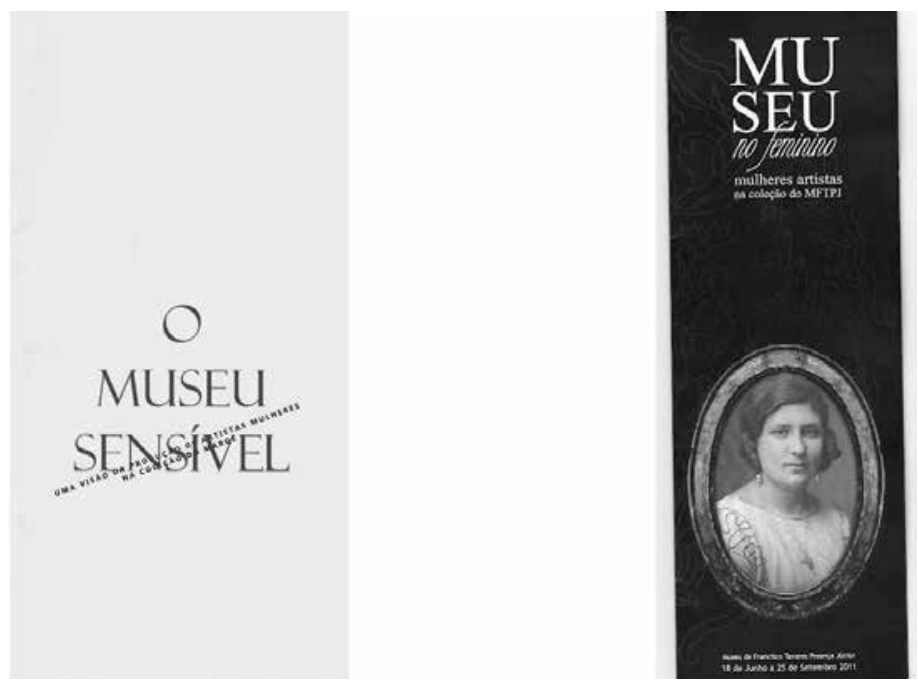

Figura 1

Imagens da capa do folheto das exposições

Com espaços físicos, volume de obras e propostas diferentes, a organização dos elementos expositivos foi também 
realizada de maneiras diferentes pelos dois museus. O MARGS adotou um modelo de disposição anticronológico das peças, dispondo-as de forma não-linear no percurso, no intuito de eliminar hierarquias. Enquanto que a curadoria do MFTPJ, sob forte influência da Sociomuseologia, justifica que primou pela formatação das obras em ordem alfabética, visto que o enfoque recaia sobre as artistas e não nas obras.

\section{Considerações finais}

A relevância das mostras $O$ Museu Sensível - uma visão da produção de artistas mulheres na coleção do MARGS e Museu no Feminino - mulheres artistas na coleção do MFTPJ demonstram a emergência de um espaço para as mulheres nas exposições museológicas, tal como vem acontecendo nas demais esferas do espaço público.

Uma exposição que trata de dar visibilidade a obra de artistas mulheres acaba por assumir-se como uma ferramenta importante para a obtenção da igualdade entre homens e mulheres. Verifica-se que a questão que se apresenta nas exposições do MARGS e do MFTPJ - da valorização das artistas mulheres nos acervos e da visibilidade de suas vidas e obras nas exposições, encontra-se dentro das preocupações atuais de igualdade de gênero vivenciadas pelas comunidades e que também são produto do pensamento da Sociomuseologia. Ao analisar o lugar da mulher artista, dentro das exposições $O$ Museu Sensível - uma visão da produção de artistas mulheres na coleção do MARGS e Museu no Feminino - mulheres artistas na coleção do MFTPJ, refletimos também sobre como a memória das mulheres artistas é preservada e promovida em cada país através de seus museus.

\section{Referências}

BARBOSA, Ana Mae. Arte no Brasil: várias minorias, In: Gênero - Niterói, V.3,N.2,(p.129-136).2003. Disponível em: http:// www.ieg.ufsc.br/admin/downloads/artigos/o2112009-014244barbosa.pdf [consulta realizada em 24/03/2012] . Educação em Museus - termos que revelam preconceitos. In: Revista Museu - cultura levada a sério. 2008. Disponível em: http://www.revistamuseu.com.br/18demaio/ artigos.asp?id=16434[consultado em 22/06/2012]

BULHÕES, Maria Amélia. Museu sensível, exposição feminis- 
ta, arte de mulheres, In: Jornal Sul 21, 23/12/2011. Disponível em: http://sul21.com.br/jornal/2011/12/museu-sensivel-exposicao-feminista-arte-de-mulheres [consultado em 22/02/2012]

CHAGAS, Mário de Souza; JÚNIOR, Nascimento. Veredas e construções de uma política nacional de museus. In: Revista Museologia. PT: IMC/MC, №1, Maio, 2007. Disponível em: http://www.ipmuseus.pt/Data/Documents/Recursos/ Publica\%C3\%A7oes/Edicoes_online/Museologia_PT/MuseologiaPT_1_Completo_II.pdf [consultado em 10/o4/2012] . A imaginação museal: Museu, memória e poder em Gustavo Barroso, Gilberto Freyre e Darcy Ribeiro, MinC/ IBRAM, Rio de Janeiro.2009

. + Direito à Memória, Rede Museu, Memória e Movimentos Sociais. 2010. Disponível em: http://redemuseusmemoriaemovimentossociais.blogspot.com/2010/o9/ direito-memoria-mario-chagas.html [consulta realizada em 02/01/2012]

. Museus e patrimônio cultural. Comunicação apresentada no I Ciclo de Palestras sobre Integração e Formação de Educadores em Espaços Culturais, Museu de Arte Leopoldo Gotuzzo (MALG), Pelotas (RS)- Brasil, 2012.

CURY, Marília Xavier. Oficina de Expografia. Museu de Arte Leopoldo Gotuzzo, Pelotas (RS) - Brasil, 2009.

Museu e Harmonia Social. In: Revista Museu - cultura levada a sério. Disponível em :http://www.revistamuseu.com.br/18demaio/artigos.asp?id=2400o[consulta realizada em 31/o1/2012]

FIDELIS, Gaudêncio. O Museu Sensível: uma visão da produção de artistas mulheres na coleção do MARGS [Catálogo]. Porto Alegre (RS): Museu de Arte do Rio Grande do Sul Ado Malagoli, 2011.

MENESES, Ulpiano Bezerra. A problemática da identidade cultural nos museus: de objetivo(de ação) a objeto (de conhecimento). São Paulo (SP). In: Anais do Museu Paulista Nova Série NQ1, p. 207-309. 1993. Disponível em: http:// www.scielo.br/pdf/anaismp/vın1/a14vını.pdf. [consultado em 11/o1/2012]

MOUTINHO, Mário. Museus e sociedade. In: Cadernos de Património, n.5. Museu Etnográfico do Monte Redondo. Disponível em: http://www.museumonteredondo.net/ images/cadernos_pat/Museus_Sociedade_II.pdf [consultado em 18/01/2012] 
Definição de Sociomuseologia: proposta de reflexão. Lisboa - Setúbal - Portugal, XIII Atelier Internacional do MINOM, 2007. Disponível em: http://redemuseusmemoriaemovimentossociais.blogspot.com/2010/o8/definicao-de-sociomuseologia-mario.html [consultado em 10/o1/2012]

PERROT, Michelle. Minha História das Mulheres, Porto: Editora ASA, 2007.

POLLOCK, Griselda. Virtual Feminist Museum. London and New York: Routledge, Time, space and archive, 2007.

RECHENA, Aida M.D. (Tese de doutorado). Sociomuseologia e Gênero: imagens da mulher em exposições de museus portugueses. Lisboa: Universidade Lusófona de Humanidades e Tecnologias, 2011a.

. Museologia e Gênero. Madrid, In: Resumos do III Seminário Iberoamericano de Investigação em Museologia (SIAM). 2011b. Disponível em: http://www.siamzo11.eu/ wp-content/uploads/2011/10/Aida-Rechena-ponencia-abstract.pdf [consultado em 12/o1/2012]

SANTOS, Maria Célia. Reflexões museológicas: caminhos de vida. Lisboa. In: Cadernos de Sociomuseologia-ULHT, n.18. 2002. Disponível em: http://www.mestrado- museologia. net/Cadernos_pdf/Cadernos_18_2002.pdf [consultado em $02 / 02 / 2012]$

SEVERINO, Antônio Joaquim. Metodologia do trabalho científico, 22º edição, São Paulo (SP): Ed. Cortez, 2002.

SIMIONI, Ana Paula Cavalcanti. A difícil arte de expor mulheres artistas. In: Cadernos Pagu n.36, p.375388, jan/jun.2011. Disponível em:http://www.scielo.br/ scielo.php?pid=So104-83332011000100014\&script $=$ sci arttext[consultado em 17/04/2012]

VICENTE, Felipa Lowdes. A Arte sem história - mulheres artistas (Sécs. XVI-XVIII). Porto. In: Artis - Revista do Instituto de Arte da Faculdade de Letras de Lisboa. N.4. 2005. Disponível em: http://www.ics.ul.pt/rdonweb-docs/Filipa\%2oVicente $\% 20 \% 20$ Publica $\% \mathrm{C}_{3} \% \mathrm{~A}_{7} \% \mathrm{C}_{3} \% \mathrm{~B}_{5} \mathrm{es} \% 2 \mathrm{O}$ 2005\%20n\% C2\%BA1.pdf [consultado em 27/01/2012]

1. Para este autor, interpretar, em sentido restrito, é posicionar-se a respeito das idéias enunciadas; superar a estrita mensagem do texto; ler nas entrelinhas; forçar o autor a um diálogo; explorar toda a fecundidade das idéias expostas relacionando-as com outras; enfim, é dialogar com o autor. (Severino, 2002:56) 
2. Conforme entrevista a Mário Chagas concedida por e-mail em o6/o8/2012.

3. Anotações da Oficina de Expografia ministrada por Marília Xavier Cury em agosto de 2009, no Museu de Arte Leopoldo Gotuzzo, localizado na cidade de Pelotas (RS) - Brasil.

4. Números coletados no website oficial do MARGS : http://www.margs. rs.gov.br [consultado em 02/05/2012]

5. Dados disponíveis em: http://wp.clicrbs.com.br/blogerlerina/2011/11/29 museu-da-mulher/ e http://www.margs.rs.gov.br/acontece_expo_aberta. php?par_id=221[consultados a 13/04/2012]

6. Disponível em: http://videos.sapo.pt/Toomjs8Gp2nYJSVjaOAU [consultado em 04/03/2012]

7. Entrevista a Gaudêncio Fidelis concedida por e-mail em 05/05/2012

8. Entrevista a Aida Rechena concedida por e-mail em 19/05/2012

9. Citação extraída do texto de apresentação da mostra O Museu Sensível, disponível no web site do MARGS. [consultado em 27/12/2011]

10. Disponível em :http://www.margs.rs.gov.br/acontece_expo_aberta.

php?par_id=221 [acesso a 27/12/2011]

Recebido em: 27/06/14

Aceito em: 10/08/14

\footnotetext{
REBECCA CORRÊA E SILVA

rebeccasilllva@yahoo.com.br

É Mestre em Gestão Cultural (2013) pela Universidade do Algarve -

Ualg e Licenciada em Artes Visuais (2009) pela Universidade Federal de Pelotas, tendo atuado como bolsista de iniciação científica - FAPERGS e pelo Programa Santander Bolsas Luso-Brasileiras.
} 